\title{
Deciding not to resuscitate in Dutch hospitals
}

Johannes J M van Delden, Paul J van der Maas, Loes Pijnenborg and Caspar W N Looman Erasmus University and Utrecht University, the Netherlands

\section{Authors' abstract}

The use of do not resuscitate (DNR) orders in Dutch hospitals was studied as part of a nationwide study on medical decisions concerning the end of life. DNR decisions are made in 6 per cent of all admissions, and 61 per cent of all in-hospital deaths were preceded by a DNR decision. We found that in only 14 per cent of the cases had the patients been involved in the DNR decision (32 per cent of competent patients).

The concept of futility is analysed as these findings are discussed. We conclude that determining the effectiveness of resuscitation is a medical judgement whereas determining the proportionality (burden/benefit ratio) of it requires a discussion between doctor and patient (or his or her surrogates). Since the respondents in the cases without patient involvement gave many reasons for their decision that went beyond determining effectiveness, we conclude that more patient involvement would have been desirable.

\section{Introduction}

In a recent editorial in the fournal of Medical Ethics Dr Gillon states that 'action is required' with respect to resuscitation policies (1). These policies are meant to ensure that decisions not to resuscitate (or do not resuscitate decisions; hereafter DNR decisions) are no longer made on an ad hoc basis. One of the essential ingredients of such a DNR policy are guidelines for the decision-making process: who is to decide what, on what basis?

As a contribution to the discussion of this theme it is useful to look first at medical practice itself. Of course the literature on DNR decisions already contains many such reports, but almost all of them stem from North America. Except for a few reports (2-4), little is known about the practice concerning DNR on this side of the Atlantic. Since medical practice in Europe differs in many respects from North America we thought it useful to describe our

\section{Key words}

Do not resuscitate orders; patient involvement in decisionmaking; medical decisions concerning the end of life; futility; therapeutic privilege; family involvement. findings with respect to DNR decisions in the Netherlands.

Although DNR decisions are frequently made in hospitals in the Netherlands, the real frequency of DNR decisions was not known. Also, discussion of the preferred DNR policy has only recently started. Most of the time, public and professional attention to life-and-death-issues centres on the euthanasia debate. In 1990 a commission (the Remmelink Commission) was set up by the Dutch government to conduct a nationwide study regarding medical decisions concerning the end of life (MDELs). In this context the decision not to resuscitate in cases of cardiac or respiratory arrest was also studied. We reported earlier on the study but did not address the DNR decision then (5) or only briefly (6). In this article we present and discuss our findings concerning the incidence of DNR decisions in hospitals in the Netherlands, and the decision-making process. In the final section we will discuss some of the normative issues related to our findings and evaluate the results.

\section{Methods}

The investigation of medical decisions concerning the end of life consisted of three studies involving general practitioners, nursing-home physicians and clinical specialists. The results discussed in this article are based on all three studies, but concern only clinical specialists. A detailed description and justification of materials and methods is given in the English edition of the original report (6).

\section{(I) INTERVIEWS WITH PHYSICIANS}

A stratified random sample of 203 clinical specialists was interviewed: 34 cardiologists, 34 surgeons, 68 specialists in internal medicine (including oncologists), 33 lung specialists and 34 neurologists. These specialties cover 89 per cent of all hospital deaths. Our target was 210 interviewees. We had to use a sample of 352 addresses to achieve the desired number of interviews. One hundred and nine physicians did not satisfy the selection criteria; 11 were not interviewed because the address was incorrect and they could not be traced; 28 (12 per cent) refused to take part; and 1 interview yielded useless 
information. The interviews were held between October 1990 and February 1991.

\section{(II) DEATH CERTIFICATES}

The cause of death of all inhabitants of the Netherlands is reported to the Central Bureau of Statistics (CBS). The name of the patient is not mentioned on the cause-of-death form but that of the reporting physician is. The medical officer in charge of cause-of-death statistics drew a stratified random sample of 7,000 deaths from all the 41,587 deaths in the Netherlands which occurred between August 1 and December 1, 1990. Of 6,942 questionnaires mailed to the attending physicians of the deaths, 76 per cent were returned, the response for in-hospital deaths being 64 per cent. The results of this study on DNR are based upon all 1,766 completed questionnaires by specialists. This study was done by researchers of the CBS in close cooperation with the authors. A separate report on this study is available in English (7).

\section{(III) PROSPECTIVE STUDY}

All interviewees in Study I were asked to participate in the prospective study by completing, for every patient in their care who died within six months of the interview and immediately after the patient's death, a questionnaire which was identical to that used in Study II. Of the 203 specialists who were interviewed, 141 (69.5 per cent) participated. The average duration of the participation was 21.6 weeks. The specialists described 1,176 deaths and the decisions (including DNR) they had or had not made. The expected number of deaths for this group of physicians during this observation period was 1,087 . Thus reporting was complete or nearly complete.

\section{QUESTIONNAIRES}

The interview schedule of study I contained a set of questions pertaining to DNR. The interviewees were asked whether they had ever made a DNR decision and, if ever, how often in the past twelve months they had done so. Respondents were asked to give this number as exactly as possible. The last patient for which a DNR decision was made was then discussed in greater detail. To find out whether the patient had been competent at the time of the decision, we asked whether the physician considered the patient to be capable of appreciating the nature of the situation he was in and of deciding adequately upon this. (The definition of competence was based upon a report of the Office of Technology Assessment (8).) Prior to the interview respondents were asked to collect information about their number of admissions and deaths per year.

The questionnaire used in studies II and III, developed in close co-operation with the CBS, consisted of 24 questions. One of these concerned the DNR decision. The question read as follows: 'Did you or a colleague clearly agree in advance that in the event of a (functional) cardiac and/or respiratory arrest no attempt would be made to resuscitate this patient? (a so-called do not resuscitate decision)'. In answering this question the respondents were able to indicate with whom they had agreed upon this decision (patient, family, colleagues, nursing staff).

We consider the respondents a stratified random sample of all specialists, their deceased patients to be representative of total mortality in hospitals and the last cases of the specialists as representative of all hospital patients with a DNR decision. All given p-values for statistical significance are based on chi-square (chi 2) tests with $\mathrm{p}<0.05$ as significance threshold. Whenever data on the same issue from the three studies do not differ significantly, only one study is described.

\section{Results}

The response among specialists selected for interviews was high ( 88 per cent) considering the length of the interviews ( 2.5 hours on average). The response of specialists to study II was relatively low (64 per cent) but the distribution of the patients' age, sex and diagnosis was identical to that for the whole Netherlands. This also applied to the protective study.

\section{INCIDENCE OF DNR DECISION}

All interviewed specialists, regardless of specialty? had at some time made a DNR decision. In most cases (96 per cent) they had done so at least once during the last year. When the reported numbers of decisions are extrapolated to all specialists we estimate that 90,800 DNR decisions were made in hospitals in 1990. The 95 per cent confidence interval (Poisson method, taking stratification into account) around this number is $88,500-93,200$. This interval may be somewhat too narrow since some specialists gave verbal estimates (for example 'almost every day', 'once or twice a week'). The distribution of these decisions over the different specialties is given in absolute numbers in Table 1 . Numbers of annual admissions from the nationwide register (9) are used to determine the DNR decisions/ admissions ratio. Calculations based upon the number of admissions given by the respondents yielded almost identical DNR/admission ratios.

Of all in-hospital deaths (the total being 53,500) 61 per cent were preceded by a DNR decision. Table 1 again shows large differences between specialties. In acute deaths there is no time to make 0 anticipating decisions at all. When these cases are $\mathbb{D}$ ignored, 80 per cent of patients die with a DNR ?decision. It is noteworthy that in this column the differences between specialties have become smaller, indicating that part of the differences in the percentage of all deaths with DNR may be explained by the percentage of acute deaths. This holds especially true for cardiologists. With 90,800 DNR decisions 


\section{Table 1 \\ Incidence of DNR decisions per specialty}

$\begin{array}{lcccc} & \begin{array}{c}\text { Estimated } \\ \text { number of } \\ \text { DNR per yr }\end{array} & \begin{array}{c}\text { DNR/number } \\ \text { annual } \\ \text { admissions 1) } \\ \text { \% }\end{array} & \begin{array}{c}\text { Deaths } \\ \text { with } \\ \text { DNR 3) } \\ \%\end{array} & \begin{array}{c}\text { Non-acute } \\ \text { deaths } \\ \text { with DNR 3) } \\ \%\end{array} \\ \text { Cardiology } & \begin{array}{c}\text { DNR } \\ \text { Surgery }\end{array} & 6 & 37 & 68 \\ \text { Int medicine } & 1,600 & 4 & 52 & 70 \\ \text { Pulmonology } & 31,800 & 15 & 68 & 83 \\ \text { Neurology } & 14,400 & 27 & 78 & 90 \\ \text { Total study population } & 16,400 & 17 & 77 & 83 \\ \text { Other spec } & 80,600 & 11 & 61 & 80 \\ \text { Total } & 10,200 & 1 & & \end{array}$

1) admission numbers are taken from reference 9 . The differences between specialties are significant (chi $2=50.2, \mathrm{df}=16, \mathrm{p}<0.001$ ).

2) Study I (n of first five rows: $33,32,62,31,31$ resp)

3) Study III (n of first five rows: $265,100,375,255,172$ )

\begin{tabular}{|c|c|c|c|c|c|c|}
\hline \multicolumn{7}{|c|}{$\begin{array}{c}\text { Table } 2 \\
\text { Discussing DNR decisions (\%) Study I }\end{array}$} \\
\hline & $\begin{array}{c}\text { Cardiologists } \\
\mathrm{n}=32\end{array}$ & $\begin{array}{c}\text { Surgeons } \\
\mathrm{n}=32\end{array}$ & $\begin{array}{l}\text { Internal } \\
\text { med spec } \\
\mathrm{n}=60\end{array}$ & $\begin{array}{l}\text { Lung } \\
\text { spec } \\
\mathrm{n}=29\end{array}$ & $\begin{array}{c}\text { Neurologists } \\
n=31\end{array}$ & $\begin{array}{l}\text { Total } \\
\text { study pop } \\
\mathrm{n}=184\end{array}$ \\
\hline $\begin{array}{l}\text { with the patient: } \\
\text { discussed, } \\
\text { pat competent }\end{array}$ & 16 & 13 & 18 & 17 & 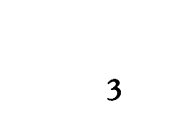 & 14 \\
\hline $\begin{array}{l}\text { not discussed, } \\
\text { pat competent }\end{array}$ & 44 & 22 & 35 & 55 & 7 & 30 \\
\hline $\begin{array}{l}\text { not discussed, } \\
\text { pat incompetent }\end{array}$ & 41 & 66 & 47 & 28 & 90 & 56 \\
\hline Total & 100 & 100 & 100 & 100 & 100 & 100 \\
\hline \multicolumn{7}{|c|}{ with others (\% in which DNR was discussed): } \\
\hline family & 25 & 38 & 25 & 24 & 52 & 32 \\
\hline colleagues & 69 & 81 & 74 & 79 & 65 & 74 \\
\hline nursing staff & 75 & 66 & 66 & 83 & 77 & 70 \\
\hline
\end{tabular}

per year and 32,000 deaths preceded by DNR, 65 per cent of DNR patients leave the hospital alive.

\section{DECISION-MAKING PROCESS}

The decision not to resuscitate was discussed with the patient in 14 per cent of all cases (Study I). The 86 per cent of the cases in which DNR was not discussed with the patient, include 56 per cent in which patients were incompetent and 30 per cent in which they were competent. Table 2 shows significant differences in this respect between the specialties (chi $2=31 \cdot 1, \mathrm{df}=8, \mathrm{p}<0.001$ ).
In all cases we asked why the decision was or was not discussed with the patient (open question). The most interesting results concern the 60 cases in which the DNR decision was not discussed with a competent patient. In 35 of these the physician stated in one way or another that this discussion would be too burdensome for the patient, thus invoking the therapeutic privilege. In 10 cases of these 35 the respondent added that for this reason it was his policy never to talk about DNR decisions with a patient.

With respect to the involvement of others (Table 2) we found at interview that DNR was discussed 
with one or more colleagues in 74 per cent of all cases and with the nursing staff in 70 per cent. Overall family involvement was 32 per cent. This 32 per cent includes 19 per cent in which only the family was involved and the patient was incompetent, 8 per cent in which only the family was involved while the patient was competent and 5 per cent in which both family and the competent patient were involved. The family was consulted in 37 per cent of all incompetent patients.

The interviewees were asked to state their reasons (open question, more than one reason allowed) for deciding not to resuscitate. The prognosis of the underlying disease was mentioned in 57 per cent of 184 cases, no prospect for recovery from the present disease in 54 per cent, low quality of life in 28 per cent, the futility of resuscitation in 27 per cent and futility of all treatment in 21 per cent. The patient's wish and 'no unnecessary prolongation of suffering' were both stated in 8 per cent of cases. Economic reasons were given in none of the cases.

In the 60 cases in which the decision was not discussed with a competent patient, the most important reasons respondents gave for their DNR decision were: bad prognosis of the underlying disease ( 58 per cent), no prospect for recovery of the present disease ( 43 per cent), a low quality of life ( 17 per cent), futility of resuscitation (30 per cent) and futility of all treatment (17 per cent).

\section{Discussion}

Since the decision not to resuscitate, made in advance, is a decision closely related to what we called a 'Medical Decision concerning the End of Life' (MDEL), this type of decision was studied as part of the Dutch nationwide study on MDELs. The three different studies yielded similar results. We found that in the Netherlands DNR decisions are being made in approximately 6 per cent of all hospital admissions and that 61 per cent of all hospital deaths were preceded by a DNR decision.

The percentage of admissions in which a DNR decision is made ( 6 per cent), is higher than that given by American studies: it is usually reported that a DNR decision is made for 3-4 per cent of all hospitalized patients (10-14), with the exception of Evans who reports 9 per cent (15). As stated, data from two different countries with different healthcare systems and different mores may not be fully comparable. A possible explanation, on the other hand, is that the incidence of DNR decisions has increased. Most of the American data stem from the early 1980s; ours are from almost ten years later. We have argued elsewhere that MDELs will increase in number (5).

In the UK two studies were recently published with data on the incidence of DNR decisions. Stewart reported DNR decisions for 31 per cent of his patients and Aarons mentioned 9 per cent for hers (2-3). Since both figures represent a point prevalence (ie the proportion of cases present at one moment in time) they are difficult to compare either with American or with Dutch incidence estimates (ie the proportion of new cases occurring during a certain period).

The percentage of deaths preceded by a DNR decision is reported to be 62 per cent- 70 per cent in the United States $(13,14,16-18)$. This coincides with our figure (61 per cent). We consider the percentage of all non-acute deaths in which a DNR decision was made ( 80 per cent), to be even more revealing since acute deaths tend to preclude advance decisions such as DNR.

We found that only 14 per cent of patients had been involved in the DNR decision. These patients constitute 32 per cent of all competent patients with DNR, which means that 68 per cent of competent patients were not involved in the DNR decision. Asplund found a similar practice of infrequent discussions with patients in Sweden (4). This contrasts rather sharply with the United States, where a large majority of competent patients are involved in the decision $(10,11,14,19)$. How, then, are these figures to be evaluated?

Looking for an explanation, one has to mention the therapeutic privilege, which was quite ofter invoked, and the concept of futility. We will concen? trate on the latter. In the Netherlands it is undero stood that non-treatment decisions based on the futility of treatment are the sole responsibility of the physician; this means that in those cases the patient does not have to be involved in the decision.

This raises two questions with respect to the results described. First: did physicians indeed think resuscitation was futile in all cases in which they did not discuss their decision with the patient? In this study they did not. In the 60 cases in which the decision was not discussed with a competent patient, the respondents gave other reasons for the DNR decision as well, for example, no prospect for recovery from the present disease, bad prognosis for the underlying disease, or bad quality of life. To argue that all these reasons are included in the concept of futility (which we would not) brings us to the second question: what exactly does it mean to say that something is (medically) futile?

The judgement 'futile' does two things: first, it implies that a certain treatment should not be carried out, and second it implies that (only) the doctor decides, because she is the expert. 'Futility' has the air of the objectivity of scientific evidence. This is what provides the justification for not involving the patient: his opinion cannot change the facts. Leaving aside the philosophical question whether such objective truths exist at all, we conclude that the test for any definition of futility is the reasonableness of the combination of the two implications.

What, then, is the definition of futility? For this two aspects should be distinguished: one concerns 
the effectiveness of the treatment and the other the proportionality (burden/benefit ratio) of it. Applying the test we just specified, we conclude that determining the effectiveness of resuscitation is a medical judgement whereas determining the proportionality is not, that is not solely. The assessment of the burden/benefit ratio of resuscitation is incomplete without the patient's perception of both the burdens and the benefits. Determining the proportionality of resuscitation is therefore a matter for discussion between doctor and patient.

Others have argued that determining the proportionality of treatment should be part of the concept of futility and should therefore be left to physicians. Schneiderman et al, for instance, argue that 'some qualitatively poor results fall outside the range of the patient's autonomy'. One of the examples they give is the 'condition requiring constant monitoring, ventilatory support, and intensive care nursing' (20). We find this position hard to maintain. Why should the patient not have the opportunity to evaluate such a condition? And what if this kind of treatment is already started for a patient in such a condition; should the treatment simply be withdrawn because doctors think it is not medically beneficial?

We do not mean to say that doctors are not entitled to opinions. It is only that opinions should not be 'medicalized'. Doctors are good judges of what a patient may be advised to choose; but it must be advice only, not a decision the patient is not even aware of. This is of course supported by the nowadays common adherence to the principle of autonomy. However, we would like to warn against an unconditional devotion to this principle. It is only by shared decision-making, not by leaving patients alone with the decision, that the mutual trust between patient and physician is strengthened.

With respect to the results we described, we conclude that in cases without patient involvement the reasons for the DNR decision quite often went beyond determining the effectiveness of resuscitation. Therefore, more patient involvement would have been desirable; there still seems to be a lot of silence between doctor and patient.

This position may be clear with respect to competent patients, but what about those patients who lack the capacity to make a decision? Does the incapacity of the patient as a decision-maker mean that no decision about the proportionality of resuscitation can be made? We submit that this would be an undesirable result. After all, resuscitation is a damaging therapy with limited chances of success.

If proportionality judgements are inevitable, as we think they are, who should make them? In the United States, family members often take over the role of the patient in the decision-making process. Present Dutch law, however, does not give family members these discretionary powers (although this might change in the near future). This probably explains why the family was involved in only 37 per cent of DNR decisions concerning incompetent patients. Still, we think more family involvement would have been desirable. Involving family members might have led the physician to discover information about the patient's wishes or helped him to reconstruct the patient's 'values history' (21). In cases where information about the patient's wishes cannot be obtained we propose that the proportionality of resuscitation be determined in dialogue between family and physician.

Several mechanisms should function as a safeguard against arbitrariness. The burden/benefit ratio should be based on what most people in these circumstances would want. The Appleton guidelines, in describing what 'persons would ordinaly want', provide a basis for such an evaluation (22). Also it should be clear that it is the benefit for this patient that is to be assessed, not the patient's benefit for society. We suggest that the evaluation should not be done by family members and attending physicians alone but that colleagues and nurses should be consulted.

In conclusion, we would like to stress that we do not think that doctors should never make value judgements. They should; otherwise they would merely be technicians. The point, however, is that these value judgements should not be made behind a veil of objectivity, leaving patients and families in ignorance.

\section{Acknowledgements}

We thank the thousands of Dutch physicians who provided information for this study, the interviewers, and our colleagues from the Central Bureau of Statistics.

The described empirical research was funded by the Dutch Ministry of Justice and the Ministry of Welfare, Health and Cultural Affairs.

fohannes $\mathcal{F} M$ van Delden, $M D, P h D$, at the time of the empirical research was a research associate at the Department of Public Health and Social Medicine, Erasmus University, Rotterdam; at present he is a research associate at the Center for Bio-ethics and Health Law, Utrecht University and works as a family physician; Paul F van der Maas, MD, PhD, is Head of the Department of Public Health and Social Medicine, Erasmus University, Rotterdam; Loes Pijnenborg, $M D$, is a research associate at the Department of Public Health and Social Medicine, Erasmus University, Rotterdam; Caspar W N Looman, MSc, is statistician at the Department of Public Health and Social Medicine, Erasmus University, Rotterdam. Correspondence to Dr van Delden, Center for Bio-ethics and Health Law, Utrecht University, Heidelberglaan 2, 3584 CS Utrecht, the Netherlands.

\section{References}

(1) Gillon R. Resuscitation policies - action required. Fournal of medical ethics 1992; 18: 115-116. 
(2) Aarons E J, Beeching N J. Survey of 'Do not resuscitate' orders in a district general hospital. British medical journal 1991; 303: 1504-1506.

(3) Stewart K, Abel K, Rai G S. Resuscitation decisions in a general hospital. British medical journal 1990; 300: 785.

(4) Asplund K, Britton M. Do Not Resuscitate orders in Swedish medical wards. Fournal of internal medicine 1990; 228: 139-145.

(5) van der Maas P J, van Delden J J M, Pijnenborg L, Looman C W N. Euthanasia and other Medical Decisions concerning the End of Life. Lancet 1991; 338: 669-674.

(6) van der Maas P J, van Delden J J M, Pijnenborg L. Medical Decisions concerning the End of Life. Amsterdam: Elsevier Science Publishers, 1992.

(7) Central Bureau of Statistics. The end of life in medical practice. Voorburg: CBS, 1992.

(8) Office of Technology Assessment (OTA). Lifesustaining technologies and the elderly. Washington: Office of Technology Assessment, 1987.

(9) SIG. Hospitals 1990 yearbook. (in Dutch) Utrecht: SIG, 1991.

(10) Uhlmann $\mathrm{R} F$, McDonald $\mathrm{W}$ J, Inui $\mathrm{T} S$. Epidemiology of No-code orders in an academic hospital. Western journal of medicine $1984 ; 140$ : 114-116.

(11) Lo B, Saika G, Strull W, Thomas E, Showstack J. 'Do Not Resuscitate decisions'. A prospective study at three teaching hospitals. Archives of internal medicine 1985; 145: 1115-1117.

(12) Lipton H L. Do Not Resuscitate decisions in a community hospital. Foumal of the American Medical Association 1986; 256: 1164-1169.
(13) Schwartz D A, Reilly P. The choice not to be resusci- $\stackrel{\mathbb{D}}{2}$ tated. Fournal of the American Geriatric Society 1986; 34: 807-811.

(14) Stolman C J, Gregory J J, Dunn D, Ripley B. @ Evaluation of the Do Not Resuscitate orders at a $\vec{\equiv}$ community hospital. Archives of internal medicine 1989; 149: 1851-1856.

(15) Evans A L, Brody B A. The Do Not Resuscitate order in teaching hospitals. Foumal of the American Medical Association 1985; 253: 2236-2239.

(16) Levy $M$ R, Lambe $M$ E, Shear C L. Do Not Resuscitate orders in a county hospital. Western journal of medicine 1984; 140: 111-113.

(17) Jonsson P V, McNamee M, Campion E W. The 'Do Not Resuscitate' order. A profile of its changing use. Archives of internal medicine 1988; 148: 2373-2375.

(18) Gleeson K, Wise S. The Do Not Resuscitate order. Still too little too late. Archives of internal medicine 1990; 150: 1057-1060.

(19) Bedell S E, Pell D, Maher P L, Cleary P D. Do Not Resuscitate orders for critically ill patients in the hospital. Foumal of the American Medical Association 1986; 256: 223-227.

(20) Schneiderman L J, Jecker N S, Jonsen A R. Medical futility: its meaning and ethical implications. Annals of internal medicine 1990; 112: 949-954.

(21) Doukas D J, McCullough L B. The values history. The evaluation of the patient's values and advance directives. Foumal of fanily practice 1991 ; 32: 145-153.

(22) Stanley J M. The Appleton International Conference; developing guidelines for decisions to forgo life prolonging medical treatment. Foumal of medic ethics 1992; 18: suppl: 1-22.

\section{Cohen and Williamson $v$ Gillon and BMA}

In Volume 17 (1991) of the Fournal of Medical Ethics we published an editorial entitled Philosophy and the Teaching of Health Care Ethics, written by the Editor, Raanan Gillon. In that article he expressed personal views about the dispute at the University College of Swansea (University of Wales) involving the Centre for the Study of Philosophy and Health Care and the Philosophy Department. In one sentence $\mathrm{Dr}$
Gillon used the word 'scurrilous' to qualify the abuse which had been directed to certain members of staff.

We have been asked to point out lest any reader should have thought otherwise that the use of the word 'scurrilous' was not intended to convey a meaning that 'obscene abuse' had been uttered as opposed to the view of Dr Gillon that abuse had been on occasion 'grossly offensive'. 